\title{
Formation of the Cast Billets Structure Under External Thermal-Power Influence
}

\author{
Nuradinov Addi ${ }^{1}{ }^{*}$, Nakhaev Magomed ${ }^{2}$, Uzdieva Natalya ${ }^{1}$ and Achtaev Salman ${ }^{1}$ \\ ${ }^{1}$ Department of Technical Sciences, Grozny State Oil Technical University, Russia \\ ${ }^{2}$ Chechen State University, Russia
}

Submission: June 25, 2020; Published: September 24, 2020

*Corresponding author: Nuradinov Addi, Department of Technical Sciences, Grozny State Oil Technical University, Russia

\begin{abstract}
The method of physical modeling was used to study the effect of superheat temperature, cooling intensity, and vibration on the formation of the cast billets structure. It was established that, using the different combinations of the considered methods of influencing the melt, it is possible to neutralize the negative effect of large overheating on the dispersion of the structure. It is clearly shown that, regardless of the level of melt overheating and the cooling intensity, vibration processing of hardened alloys with high efficiency ensures the formation of a favorable structure of the cast billets.
\end{abstract}

Keywords: Vibration; Melt; Overheat; Cooling intensity; Hypothermia; Crystallization; Billet; Structure

\section{Introduction}

An urgent problem of modern engineering is increasing the technical level of the machines and the aggregates, which imposes increasingly stringent requirements on the quality of the metal products used in this. It will not be possible to solve this problem without improving metallurgical technologies along the entire chain from metal smelting to obtaining finished products. One of the possible ways to improve the quality of metals and alloys is improving the technology for producing cast billets from them, namely, the impact of various external methods on liquid and hardened melt [1-4].

During the transition from a liquid to a solid state, metal melts can be in a nonequilibrium state on both sides of "melt - crystal" phase transition due to the slow occurrence of changes in their microscopic characteristics. It is known that melt relaxation processes (establishing microscopic homogeneity) can be boosted by various external influences on it, including thermal and physical influences [5-8]. So, researches aimed at establishing the fundamental laws of the formation of the structure of the cast billets under external thermo-force effects on alloys of various nature during their melting and crystallization are relevant.

The leading role in the formation of the structure and physicomechanical characteristics of the cast metal is played by the process of solidification, the nature of which is determined by two interrelated parameters: crystallization rate $(R)$ and the value of supercooling at the phase boundary $\left(\Delta \mathrm{t}_{\mathrm{k}}\right)$. The values of these parameters depend on many factors: metal purity, superheat temperature exposure time and melt cooling intensity, etc. The connection between crystallization rate and supercooling is determined by the following relationship [3]:

$$
R=k \cdot \Delta t_{k}
$$

where $\mathrm{k}$ - hardening coefficient, $\mathrm{m} / \mathrm{s}^{0,5}$.

The main characteristic of the dendritic structure also depends on the crystallization rate of the melt [6]:

$$
\lambda_{1}^{4}=\text { A.C/G.R }
$$

where $\lambda_{1}$ - distance between first order axes; A - experimental coefficient; C - initial concentration of liquor impurities; G temperature gradient before the solid phase boundary.

It is known from the practice that the final metal products made from the cast billets with a dispersed crystalline structure, minimal segregation and a favorable arrangement of non-metallic inclusions have the highest level of mechanical properties. In order to obtain a cast metal with this structure, it is necessary to ensure maximum crystallization speed and the amount of cooling over the phase boundary, which, when forming real steel blanks as the thickness of the hardened metal crust increases progressively (5-10 times), which in turn leads to the emergence of structural zones of different dispersion and shape. 


\section{Materials and Methods}

In this work, we studied the complex effect of various external factors (superheat temperature, cooling intensity, and vibration) on the supercooling of melts and the formation of the structure of model (camphene) and metal (aluminum A5) alloys.

\section{Results and Discussion}

The influence of the melt overheating temperature and its cooling intensity can be judged not only by increasing or decreasing the rate of melt crystallization, but also by the change in the nucleation rate and their growth morphology (Figure 1). A comparison of the structures of the identical zones of the test billets showed that the most favorable dispersion of the crystal structure of the model alloy is observed with minimal melt overheating (Figure 1, compare a, b, and c). These information are fully consistent with the recommendations determined by casting practice on casting steel melts at a liquidus temperature in the range of not more than $30-50^{\circ} \mathrm{C}$. At higher temperatures, the grain size increases and the intergrains are enriched with non-metallic inclusions [9].
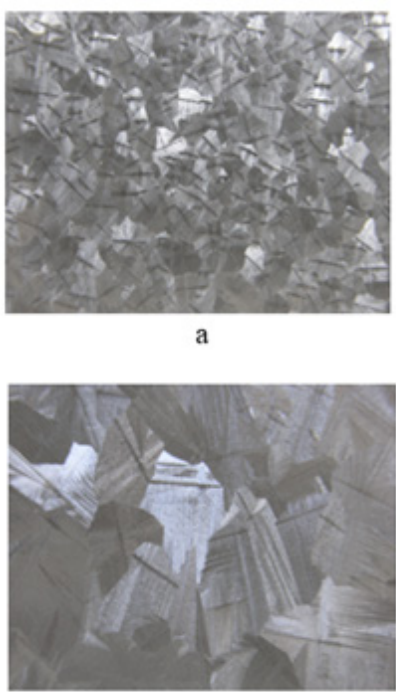

d

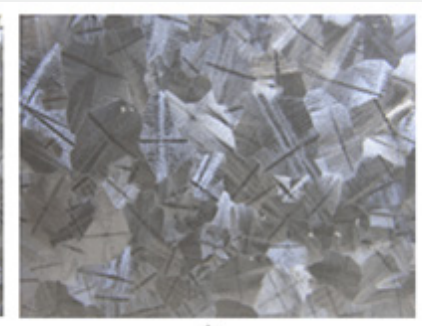

b

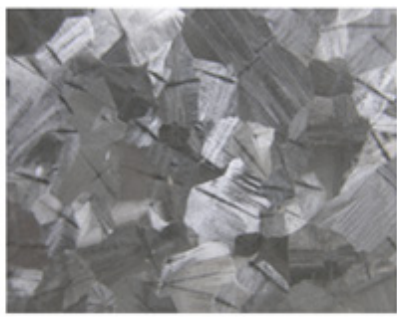

e

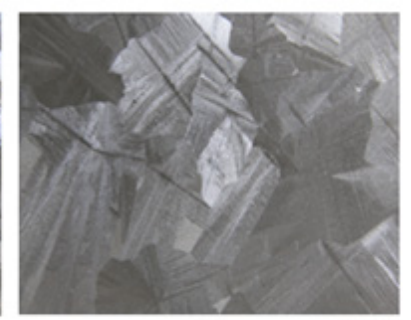

c

$\mathrm{x} 5$

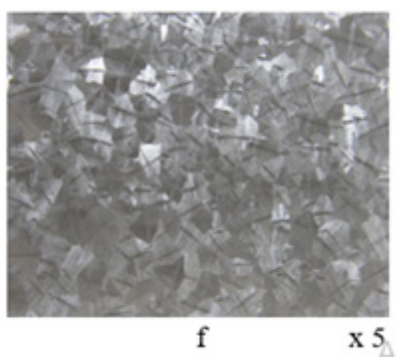

Figure 1: Camphene macrostructure depending on superheat temperature and cooling rate of solidified melt:

$\mathrm{a}-\Delta \mathrm{t}_{\text {over. }}=2^{\circ} \mathrm{C} ; \mathrm{b}-\Delta \mathrm{t}_{\text {over. }}=4^{\circ} \mathrm{C} ; \mathrm{c}-\Delta \mathrm{t}_{\text {over. }}=8^{\circ} \mathrm{C} ; \mathrm{a}, \mathrm{b}, \mathrm{c}-\mathrm{W}_{\text {cool. }}=6^{\circ} \mathrm{C} / \mathrm{min} ; \mathrm{d}-\mathrm{W}_{\text {cool. }}=6^{\circ} \mathrm{C} / \mathrm{min}$.; e $-\mathrm{W}_{\text {cool. }}=16^{\circ} \mathrm{C} / \mathrm{min}$.; $\mathrm{f}-\mathrm{W}_{\text {cool. }}=35^{\circ} \mathrm{C} / \mathrm{min}$; $\mathrm{d}, \mathrm{e}, \mathrm{f}-\Delta \mathrm{t}_{\text {over. }}=8^{\circ} \mathrm{C}$.

The negative effect of large overheating on the dispersion of the dendritic structure of the billets can be practically leveled by regulating the intensity of heat removal, namely, supercooling and crystallization rate (Figure 1, compare d, e, and f). From these results we see a clear relationship between the dispersion of the structure of the billets and the supercooling of the hardened metal, which, in turn, depends on the concentration of impurities dissolved in the melt [10]. This is evidenced by the dependence of the magnitude of the supercooling of the molten metal on the heating rate and the exposure time in the superheated state, since the diffusion of impurities is difficult both during heating and during cooling. (Figure 2).

In fact, we see that gallium subcooling depends on both the heating rate $\mathrm{Wp}$ and the holding time $\tau$. For example, at a heating rate of $30^{\circ} \mathrm{C} / \mathrm{min}$., when we increase the exposure time in an overheated state from 2 to 30 minutes, the value of supercooling doubles. (compare curves 1 and 4, Figure 2). It is clear that when the temperature of overheating increases, the concentration of dissolved admixture in the melt increases and for its subsequent condensation more percolation is needed, than in our opinion, and explains the above dependence.

Sometimes in practice, in order to transfer a metal melt to an equilibrium state, it is necessary to ensure high values of the superheat temperature, which is the main reason for the formation of a coarse-grained crystalline structure [11,12]. However, it is not always possible to ensure a high melt crystallization rate to eliminate the negative effect of overheating on the formation of the structure. In such cases, vibration can be used as the most effective way to eliminate the negative effect of large overheating on the dispersion of the structure during solidification of metal alloys. In the works $[3,4,13,14]$ the significant impact of vibration on the processes of crystallization and structure formation of metal alloys for normal overheating of their melts (up to $50^{\circ} \mathrm{C}$ ) has been proved. 


\section{Insights in Mining Science \& Technology}

In this work, it was found that vibration dramatically changes the macro- and microstructure of the model alloy even for large overheats $\left(\Delta \mathrm{t}_{\text {over }}=12^{\circ} \mathrm{C}\right)$ and low cooling rates $\left(\mathrm{W}_{\text {cool }}=6^{\circ} \mathrm{C} / \mathrm{min}\right.$. $)$. These values are equivalent to overheating of medium-carbon steels at $250-300^{\circ} \mathrm{C}$ and their solidification in sand form. In the control experiment, the macrostructure of the ingot consists of large columnar and equiaxed crystals of irregular shape, while under the action of vibration a uniform granular structure of high dispersion is formed over almost the entire cross section, with the exception of a small zone of dispersed columnar crystals on the heat-sinking surfaces of the form (Figure $2 \& 3$, a and b).

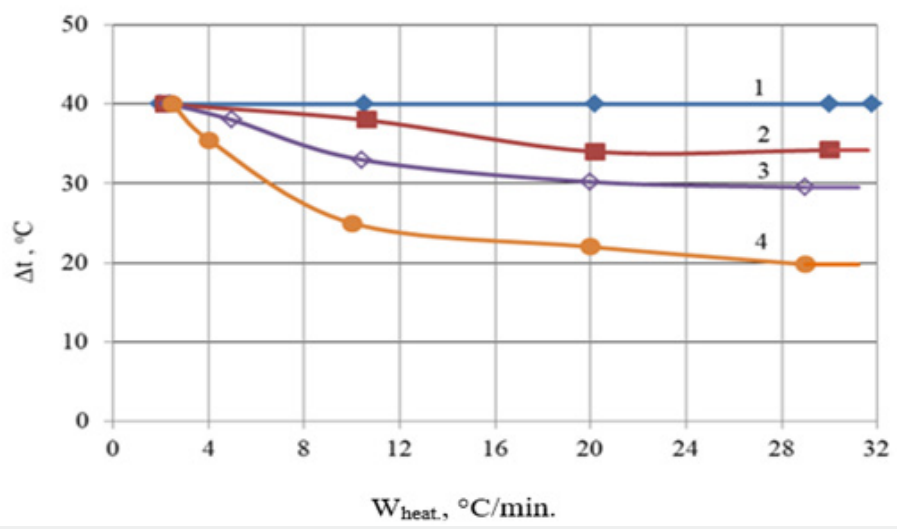

Figure 2: Dependence of gallium supercooling on the heating rate at different exposures in an overheated state: $1-\mathrm{T}=30 \mathrm{~min} ; 2-\mathrm{T}=20$ $\min ; 3-\mathrm{T}=10 \mathrm{~min} ; 4-\mathrm{T}=2 \mathrm{~min}$.

The effect of vibration is also manifested on the microstructure of the model alloy (Figure 3, c and d). During ordinary solidification of the alloy, a microstructure with an unfavorable block structure is formed, while the interface between the blocks is clearly visible
(Figure 3, c). After the action of vibration, the microstructure of the alloy is characterized by the absence of block structure and clear boundaries of the primary grain, as well as their greater uniformity and dispersion (Figure 3, d).
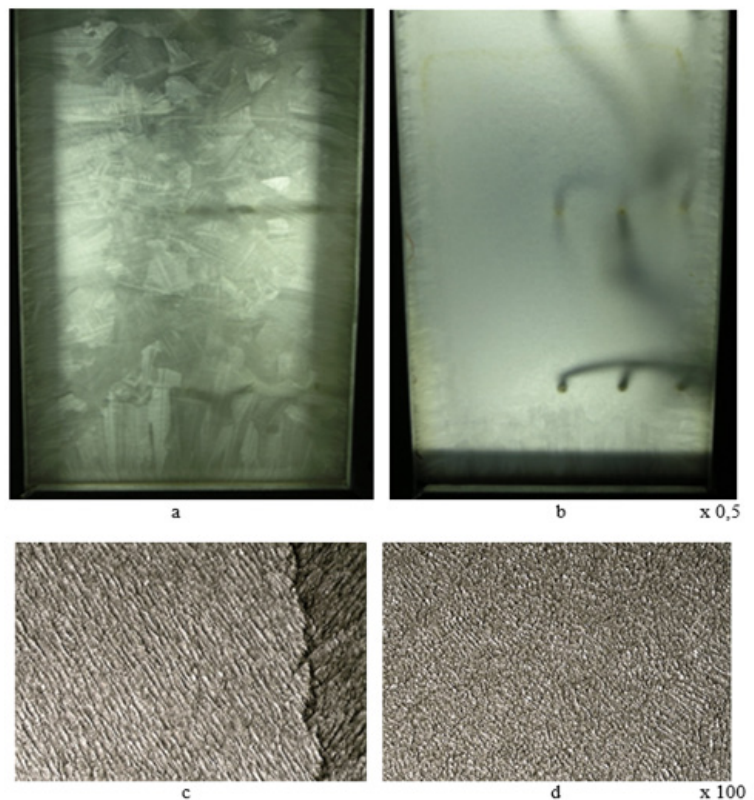

Figure 3: The macro- and microstructure of the camphene when melt overheats

$\Delta$ tover. $=12^{\circ} \mathrm{C}$ and cooling rate $\mathrm{W}_{\text {cool. }}=6^{\circ} \mathrm{C} / \mathrm{min} . \mathrm{a}, \mathrm{c}-$ no vibration; $\mathrm{b}, \mathrm{d}-$ under vibration. 
To verify the correctness of the results of physical modeling, researches were carried out to study the effect of superheat temperature, heat sink intensity and vibration on the formation of the structure of ingots from A5 aluminum alloy. The heat sink intensity in the experiments was varied in that the melt superheated to the same temperature was poured into metal molds with different wall thicknesses (steel molds with wall thicknesses $\delta=1,10$, and $20 \mathrm{~mm}$.). The temperature curves of cooling of the hardening melt were constructed using direct temperature measurements using thermocouples. The macroand microstructures of the ingots were developed according to standard methods.

The temperature of the melt overheating occupies a special position from the various characteristics of the thermal state of the "ingot-form" system, which determine the initial conditions for the formation of the structure of the ingots. It is not only a characteristic of the thermal conditions of metal casting, but also a parameter of the physical state of the melt at the time of crystallization, which influence to a large extent the formation of the crystalline structure of the metal at macro and micro levels, as well as the degree of its physical homogeneity.

It is known that the main responsibility for the formation of the structure, physico-mechanical and service properties of cast metal lies on the crystallization of the melt, the nature of which is determined by the heat sink intensity from it. Figure 4 shows the temperature curves of cooling of hardening aluminum alloy A5 depending on the heat sink intensity. It can be seen that, depending on the material of the molds and the thickness of their walls, the cooling rate of hardening melts varies over a wide range (from $0.3^{\circ} \mathrm{C} / \mathrm{s}$ for a vologran form to $5^{\circ} \mathrm{C} / \mathrm{s}$ for a steel mold with a wall thickness of $20 \mathrm{~mm}$ ). The total solidification time of the ingots varies according to the cooling rates and is reduced by about 6 times for extreme options.
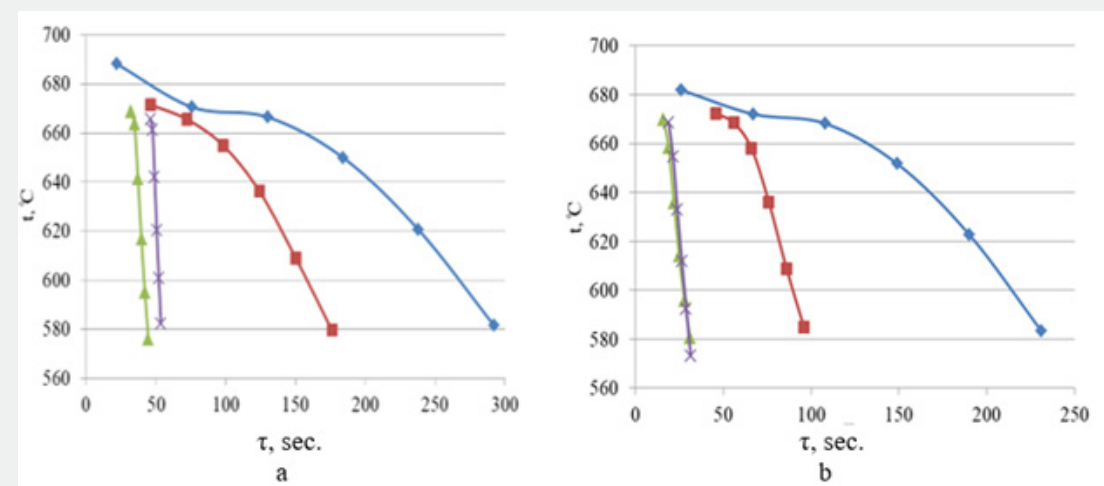

Figure 4: Temperature curves of cooling of hardening aluminum alloy A5: $\boldsymbol{\Delta}-$ metal form with $\delta=20 \mathrm{~mm} ; \mathrm{x}-$ metal form with $\delta=10 \mathrm{~mm}$; - - metal form with $\delta=1 \mathrm{~mm} ;-$ vologran form; $a$ - control option (without vibration); $b$ - under the influence of vibration: $A=0,2 \mathrm{~mm}$.; $v$ $=60 \mathrm{~Hz}$

When vibrating the hardening metal, there is a more heat sink intense from it:: on average, for all options, the cooling rate of hardening melts increases by 1.6 times, and the total solidification time of ingots decreases by more than 1.5 times (Figure 4, b). A comparative analysis of the macrostructure of the ingots of the studied aluminum alloy $\mathrm{A} 5\left(\mathrm{t}_{\text {lik. }}=657^{\circ} \mathrm{C}\right)$, obtained even for very high superheat temperatures $\left(\mathrm{t}_{\text {over. }}=860^{\circ} \mathrm{C}\right)$, shows their good correlation with the results of physical modeling (Figure 5). The structure of all control ingots consists of zones of columnar crystals, the dispersion of which is determined by the heat sink intensity (Figure 5, a, b and c).

The results are of a very different nature when the structures of ingots are formed under the influence of vibration (the vibration parameters in these studies were the following: amplitude $A=0.2$ $\mathrm{mm}$; frequency $v=60 \mathrm{~Hz}$ ). A large part of the area of macro- thin sections of the ingots is occupied by a uniform granular structure of high dispersion (Figure $5 \mathrm{~d}$, e and f). With a significant increase in the heat sink intensity (solidification of ingots in metal forms with wall thicknesses $\delta=10$ and $20 \mathrm{~mm}$ ), a small zone of dispersed columnar crystals around the perimeter is preserved in the cross section of the ingots (similar to physical modeling, see Figure 3, b).

As for the microstructure, in the surface zones of all ingots it practically does not differ from each other and are dispersed crystals of aluminum $\left(\mathrm{Al}_{\alpha}\right)$ solid solution and eutectic $\mathrm{Al}_{\alpha}+\mathrm{Si}$. In ingots obtained without vibration, as the grain is removed to the center, the size of the grain increases and more complex eutectics $\mathrm{Al}_{\alpha}+\mathrm{Si}, \mathrm{Mg}_{2} \mathrm{Si}, \mathrm{Mg}_{5} \mathrm{Si}_{8}$ appear in the form of a dark grid along the boundaries of the grains $\mathrm{Al}_{\alpha}$ (Figure 6, a and b).

In vibration-treated ingots, dispersed grains are preserved in the central zones, but there is a slight decrease in the volume fraction of the eutectic and a more uniform distribution of it (Figure 6,c), which indicates the destruction of interatomic bonds in clusters of the type $\mathrm{Mg}_{x} \mathrm{Si}_{y^{\prime}}$. As a result, a supersaturated solid solution of aluminum with a higher microhardness is formed. 


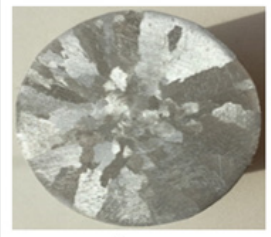

a

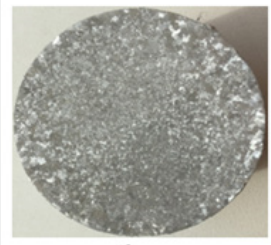

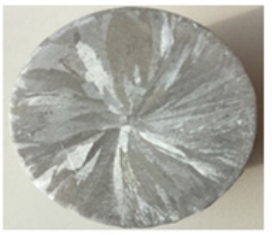

b

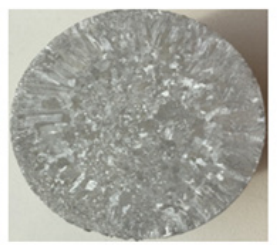

$\mathrm{e}$
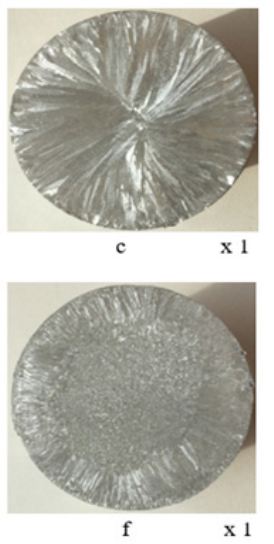

Figure 5: Macrostructures of experimental ingots from aluminum alloy A5: $a, d-$ metal form with $\delta=1 \mathrm{~mm} ; \mathrm{b}, \mathrm{e}-$ metal form with $\delta=10$ $\mathrm{mm} ; \mathrm{c}, \mathrm{f}$ - metal form with $\delta=20 \mathrm{~mm} ; \mathrm{a}, \mathrm{b}, \mathrm{c}$ - control option (without vibration); $d, e, f-$ under the influence of vibration: $A=0.2 \mathrm{~mm} ; \mathrm{v}=$ $60 \mathrm{~Hz}$.

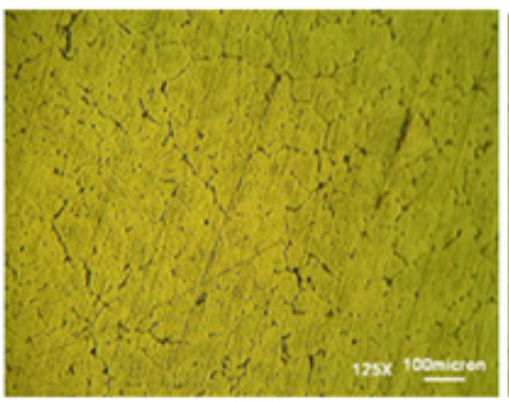

a

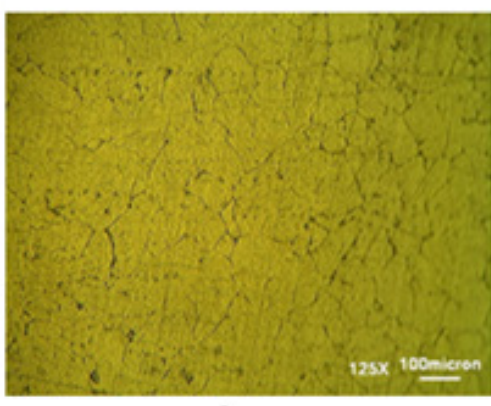

b

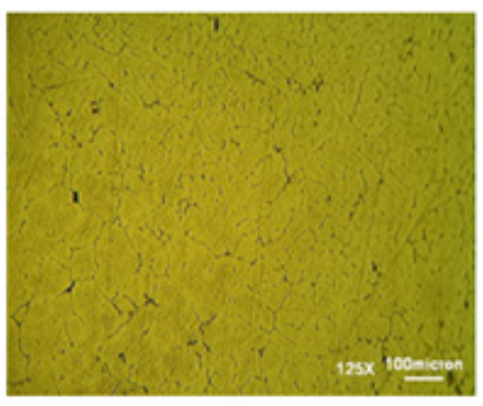

c

Figure 6: Microstructure of axial zones of ingots from aluminum alloy A5: $a, b-$ control; $c$ - with vibration $a, c-$ metal form with $\delta=1 \mathrm{~mm}$; $b-$ metal form with $\delta=20 \mathrm{~mm}$.

\section{Conclusion}

Thus, the results open up the prospect of developing new metallurgical technologies for the effective management of the cast metal structure at the first stage of production of billets. In addition, the considered methods of controlling the formation of the structure of the cast billets in some cases can be an alternative to environmentally harmful operations of chemical modification of metals and an effective factor in resource and energy conservation.

\section{References}

1. Gavrilin IV (2000) Melting and crystallization of metals and alloys. Vladimir VITU pp. 255.

2. Abramov VO, Abramov OV, Artemyev VV (2006) Powerful ultrasound in metallurgy and mechanical engineering. M Janus K, pp. 688.

3. Efimov VA, Eldarkhanov AS (2004) Technologies of modern metallurgy. M New technologies, pp. 784.

4. Eldarkhanov AS, Nuradinov AS, Akhtaev SSS (2019) The influence of external thermo-force effects on the formation of the cast billets structure. Steel 6: 9-13.

5. Ovsienko DE (1994) The nucleation and growth of crystals from the melt. K Naukova dumka pp. 256.

6. Herlach D, Firebach B (1989) Nucleation and hypothermia. Space materials science. M World, pp. 179.

7. Baum BA (1979) Metallic fluids - problems and hypotheses. M Science pp. 120.

8. Flemings M (1977) Hardening processes. M Metallurgy, pp. 424.

9. Kondratyuk SE, Parkhomchuk JV, Weiss VI (2018) Thermokinetic parameters of melt processing and structure formation of cast steel. Metallurgy and metal processing 4: 9-18.

10. Nuradinov AS (1997) The effect of overheating, ultrasound and pressure on the value of the limiting supercooling of an alloy. Casting processes 2: 17-20.

11. Baum BA (1979) Metallic fluids - problems and hypotheses. M Science pp. 120.

12. Balandin GF (1973) The formation of the crystalline structure of the casting. M Engineering pp. 288. 
13. Campbell J (1981) Effects of vibration during Solidification. Internationale Metals Reviewers 26: 71-108.
14. Naydek VL, Eldarkhanov AS, Nuradinov AS (2003) On the mechanism of the effect of vibration on the crystallization and structure formation of alloys. Foundry 9: 13-15.

DOI: $10.19080 / I M S T .2020 .02 .555584$ 